\title{
Visual Communication in Virtual 3D Learning Environments
}

\author{
Caterina Poggi, Nicoletta Di Blas, \\ Politecnico di Milano, Italy \\ \{poggi,diblas\}@elet.polimi.it
}

\begin{abstract}
How does visual communication in multi-user educational $3 D$ environments support interaction and collaboration? To what extent does it affect learning? How can it be improved? We investigate the role of visual communication in $3 D$ virtual reality basing on our 8-years experience of VR-based educational projects, tested with good results by thousands of users from 17 countries. We identify 3 key aspects strongly related to the visual nature of VR, contributing to the success of collaborative experiences: virtual presence, proxemic semiotics, and peripheral awareness.
\end{abstract}

\section{Introduction}

Since 1999, the HOC laboratory of Politecnico di Milano designs educational programs based on virtual reality: Virtual Leonardo, a cooperative virtual visit to the Museum of Science and Technology in Milan; $S E E$, an adventure for high-school students in the Israel Museum of Jerusalem; Stori@Lombardia, on medieval times in Italy, and Learning@Europe, about European nation-states. In all of them, users meet and interact in a synchronous shared virtual environment.

These "educational experiences" imply traditional activities (study, research, homework) and less traditional ones: creating HTML pages, interacting on forums and in a 3D world. Online sessions are the core of the experience, and its most exciting part. Results of systematic monitoring over the years confirm the validity of these programs, both in terms of customer satisfaction and of educational benefits.

What is the specific role of the 3D world? To what extent do the educational benefits depend on it? How does visual communication in the $3 \mathrm{D}$ world support students' interaction? How can it be improved?

This paper investigates the role of visual communication in 3D educational environments. After describing previous related work, we provide an overview of our VR-based educational experiences, and some figures on its implementation phases. We then illustrate the main benefits of the visual element in our projects. Finally we discuss 3 key features of 3D virtual worlds: "virtual presence" (the sense of "being there" in a situation with other people); "proxemic semiotics" (i.e. the signs conveyed by movements and positions in space); and "peripheral awareness".

\section{Related work}

Virtual reality is an especially "visual" technology, capable of showing virtual objects from different perspectives, allowing users to move and to manipulate them. Virtual reality can also "immerse" users into a virtual world, and give them the feeling of being, moving and acting in a different place. The subjective feeling of "being there" in a place different from one's physical location is called virtual presence [1-3].

For these characteristic virtual reality has been used for different purposes: to represent abstract scientific concepts, such as electromagnetic fields [4], geometry constructs [5], complex environmental issues [6], or the variables regulating the solar system [7]. Accurate 3D reproductions of historical sites make possible an architectural walkthrough in ancient Olympia [8], in an ancient Greek house [9], or at Monticello [10]. Simulations are used for military or medical training, in exposure therapy for treating psychological disorders, such as social phobia [11], fear of spiders [12], fear of flying and claustrophobia. Finally, collaborative virtual experiences engage students in complex interactions with the $3 \mathrm{D}$ environment and with other users, while teaching scientific research methods as in River City [13], social and ecological issues as in Quest Atlantis [14], or identity and moral values as in Zora [15].

While simulations stress the high fidelity of digital reproductions, we contend that high-quality graphics is neither sufficient nor necessary to produce successful virtual 3D-worlds. Virtual reality is effective when it produces virtual presence, and realism is only one of the factors believed to enhance it. Control, distraction, and sensory input are also important [2]. When users control their movements in the 3D world, see their virtual counterpart doing what it is expected to do and 
the 3D world changing accordingly, their sense of personal and environmental presence [1] is reinforced. No external distractions - or breaks in presence [3] should interrupt the stream of stimuli coming from the virtual world. The stream of sensory data should be consistent through different modalities, and reflect if possible the richness and variety of sensory information that we experience in real life [2].

Collaborative virtual environments also afford social presence [1]: the extent to which interaction with remote users is perceived as sociable, warm, or personal, generating the sense of "being together".

Due to the visual nature of virtual environments, proxemic semiotics [16] can play an important role. All the signs an agent conveys by means of his/her actions and position in space are proxemic semiotics phenomena. An avatar moving towards a door is "telling" the others where it is going. It is up to the designer to decide how many proxemic signs the avatars will convey: if virtual objects mimic real world constraints, more information is conveyed than when avatars do everything with a click.

The visual nature of virtual collaborative spaces also makes it easier to reach peripheral awareness. At any moment, users in the 3D world may want to know where everyone else is, and what they are doing. "Awareness of individual and group activities is critical to successful collaboration and is commonly supported in $\mathrm{CSCW}$ systems by active, information generation mechanisms" [17]. In virtual environments users need only to look around and see what other avatars are up to. Awareness can be immediate and natural: if the spaces allow a user to see everyone else at once, and if a look at the avatar is enough to know what it is doing, no active notification or request of information is necessary. If visual features allow users to express their emotional states, or indicate their role, also social and group-structural awareness [18] become immediate.

\section{Case Study}

This section presents the evolution of the virtual environments developed by our team. The technology also evolved from the initial platform Webtalk1 [19] to the current version Webtalk04 [20].

\subsection{Evolution of virtual experiences}

The first shared virtual environment developed by the Hypermedia Open Center at Politecnico di Milano in 1999 was Virtual Leonardo: a virtual exhibit of the Science and Technologies Museum in Milan, showing the machines invented by Leonardo da Vinci (Fig. 1).

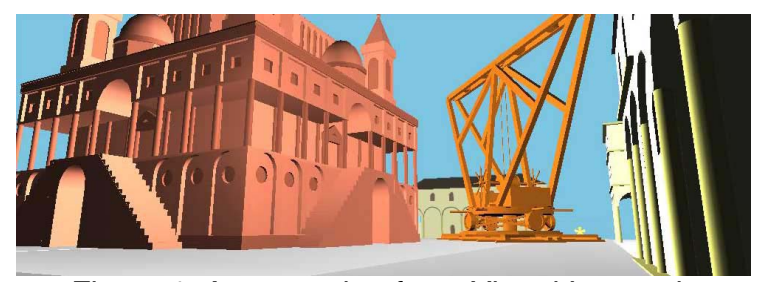

Figure 1. A screenshot from Virtual Leonardo

Users could access the virtual museum anytime, walk and fly, see and activate Leonardo's machines, meet Leonardo (a virtual agent, at times controlled by a museum guide) and other visitors, and interact with them via chat [21]. While users enjoyed chatting with each other, their conversations were shallow; besides, they did not always find company.

The subsequent project, SEE - Shrine Educational Experience started in 2001 with the Israel Museum, Jerusalem. In order to engage high school students in richer cultural interactions, we designed a 6-weeks long experience where classes of students from 4 different countries meet in a 3D world for 4 times [22]. They study educational content before online sessions, and in the meetings (about 1 hour long) they discuss the material under the supervision of a "guide", play games, and explore the virtual Israel Museum (Fig. 2).

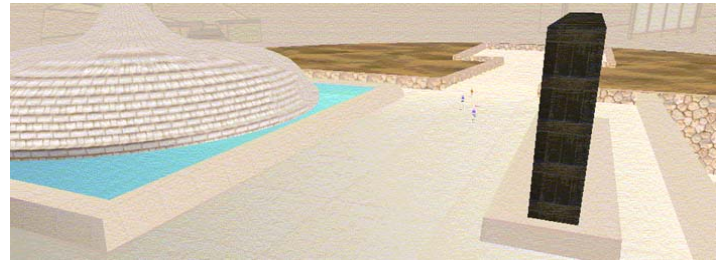

Figure 2. The virtual Israel Museum in SEE.

Between 2002 and 2004 SEE was field-tested with over 1500 students and teachers from Italy, Israel and Belgium, with very satisfactory results [23-24].

Two similar educational projects were developed in 2004: Learning@Europe (L@E), on nation-states in Europe, and Stori@Lombardia (S@L), about medieval city-states in the Italian region of Lombardy.

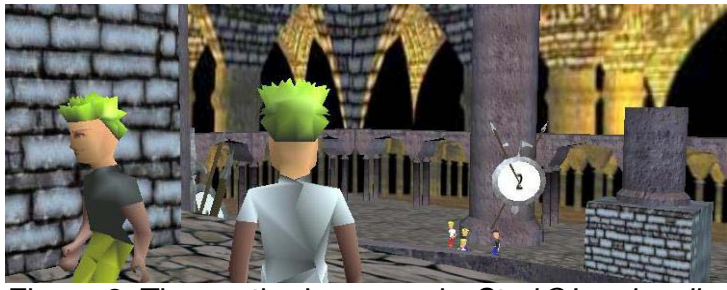

Figure 3. The castle dungeons in Stori@Lombardia.

Major innovations with respect to SEE include an additional "2D" chat panel, a second "guide", and online forums for asynchronous collaboration. 


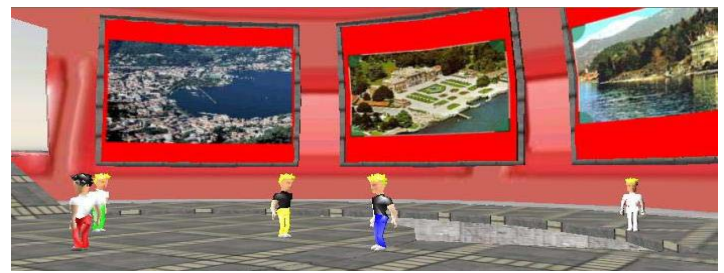

Figure 4. Avatars on Learning@ Europe planet.

The first implementation of L@E and S@L in Spring 2005 involved in total about 1700 teachers and students from 6 European countries [25]. The second phase (November 2005 - June 2006) involved about 3500 participants from 16 European countries.

While the first two virtual environments reproduced a museum, which "real" visitors would be able to recognize, S@L takes place in a virtual medieval castle (Fig. 3), whereas L@E spaces represent an imaginary high-tech planet (Fig. 4). It became clear in time that our virtual worlds do not need to reproduce real places. However accurate the simulation, a virtual museum can never convey the "magic" of being in front of the authentic object. Rather, the virtual experience must engage users in meaningful interactions with each other, the educational contents, and the environment. The sequence of activities therefore is central to the design of the visual features in the $3 \mathrm{D}$ environment.

\subsection{Structure of a $L @ E$ virtual experience}

This paragraph briefly describes an experience in Learning@Europe.

Every L@E experience involves 4 classes of students (aged 15 to 18) from different European countries. The "official" language is English. Classes are paired to form two teams, which will engage in a competition lasting 6-8 weeks. Participants meet 4 times in a shared online 3D world; before each session students must read educational material and complete assignments, working with team partner on the forums.

During the sessions, in each school the class groups around 4 computers: 2 for moving and interacting in the $3 \mathrm{D}$ environment, and 2 for writing in a " $2 \mathrm{D}$ " chat without 3D graphics. Two guides from the staff direct the activities, stimulate discussions, and fire questions at the students to test their preparation. Correct answers earn points for the team.

Sessions include a discussion about the educational material, a presentation of the students' works, and a game, requiring "physical" skill (e.g. flying through circles), collaboration with remote users (guiding "blind" team partners through a path), knowledge of the contents (selecting objects according to a clue) or all of the above. Quizzes and visual content are embedded in the 3D world as textures of $3 \mathrm{D}$ objects or HTML pop-up windows activated from 3D hotspots.

\subsection{Evaluation of $L @ E$}

The first implementation of L@E (in March-May 2005) involved nearly 50 teachers and 1000 students aged 15 to 18, from 33 European high schools. About $20 \%$ of teachers and $45.2 \%$ of students used computers less than 3 hours a week. Participants came from Italy, Poland, Spain, France, Belgium, and Norway. 48 sessions (each involving 4 classes) were completed.

We collected data from a variety of sources, to ensure triangulation of findings. Teachers completed a survey before the beginning of the project and one after each session (response rate: about 85\%); 12 teachers also took part in a focus group after the conclusion of the project. Students completed a survey before the beginning and one after the end of the experience (response rate: $40-60 \%$ ); all their works were collected and evaluated. Guides wrote a report after each session. System data include: chat logs of all 48 sessions, messages of 41 forums, screen-registrations of 12 sessions; quantitative and qualitative analysis is being performed on these data. Experts from the Universities of Georgia and Maryland provided independent reviews of results. Observers in schools videotaped 7 hours of class interaction.

Teachers reported above-average improvements (compared to usual school activities) in their students' knowledge of history (65\%), technological skills (89\%), group work (95\%), English (75\%), curiosity for other cultures $(79 \%)$, and motivation (84\%). Guides reported that in $80 \%$ of sessions students answered correctly to most questions. The quality of studentproduced artefacts shows their learning. 89\% of teachers rated L@E educational impact good or very good. Results of year 2005-06 (88.5\%) confirm this trend. Detailed data reports can be found on L@E website (www.learningateurope.net).

\section{Why a virtual world?}

Is a virtual world educationally effective for learning about history? Is the visual 3D graphics really necessary? Data suggest that the 3D environment strengthens the sense of virtual presence, offers visual "back channels" such as proxemic signs and visual common ground, and makes peripheral awareness more natural, speeding up collaboration.

The 3D worlds provide a powerful stream of visual information, that may strongly influence presence [2]. Control and realism also intervene more substantially in a 3D environment; personal and environmental presence [1] are much stronger than in a chat.

However, social presence can be achieved also via chat or forum. Distraction occurs more frequently in 
the 3D world, where minor technical impasses can cause breaks in presence [3]. Intellectual involvement in the "2D" chat was often observed to be even more intense than in a 3D world.

Yet, observers and teachers reported that students would 'fight' for the role of 3D player. Data clearly show the students' excitement at exploring the virtual world, flying, "seeing" other people and competing with them in the games. The 3D captured the attention not only of the players, but also of the 6-7 classmates standing behind them, supporting and cheering. In average 87 messages in every chat log were coded for 'involvement', the majority referring to actions in the 3D world (e.g. "I'm flying!!'). Guides reported that in $90.7 \%$ of the sessions most students seemed engaged, motivated, excited: as shown in the comment below, involvement results from the combination of chatting with remote peers, competing with them, and moving around the 3D world. "The students were very curious and involved. They explored the 3D planet autonomously and they were very excited for their new planet. When the session ended, the students were sad and they would rather stay on the $3 D$ planet."

The avatars convey a large amount of significant information just by their position and movements. Guides and observers reported that disoriented users tended to look for other users and follow them, with no need to call for help. When an avatar remained alone, the guide teleported near it: the user happily followed the guide, rather than a set of complex instructions.

Sharing the same visual context also extends the users' common ground [26], i.e. the part of the world that interlocutors share and to which they can refer. When the guide says "follow me through this door", people recognize the door just by looking at the guide.

L@E discussion spaces are designed in a way that every user can see at any moment where the others are, and guess what they are doing. An avatar standing still may either be reading or writing in the chat, or looking at pop-up content. We are planning to introduce visual indicators of the avatar's actions (e.g. "mumble" cloud over the avatar's head when it is writing a message).

Also, the guides' avatars are easy to recognize as they are clothed all in white. Student-avatars' shirts and pants are color-coded to indicate their team and class, shown in color also on the control panel.

\section{Conclusions and Future Steps}

We believe that the visual nature of virtual reality provides significant advantages in what for many users is an adventure in unknown territory. These should be considered in designing shared virtual worlds.
* The 3D creates involvement and engagement, shows students that "the others" are there, conveys the sense of "moving" deeper into an experience.

* The 3D (especially with the help of a video projector) involves more people besides the student at the keyboard: it generates "extended" virtual presence.

* High-quality 3D graphics is not essential, as long as students are engaged in meaningful activities.

The role of visual communication in 3D multi-user environments needs further research. We plan to:

- Investigate "extended" virtual presence: to what extent does it depend on the visual aspects of the 3D? An analysis of videos of class interaction and data on 2D chat users vs. 3D players can provide answers.

- Investigate proxemic signs in the 3D world, by comparing "powerful" avatars and avatars with heavy constraints. By cross-analyzing their movements and the chat, we can identify information shifts from the visual to the verbal channel and vice versa, and draw guidelines for balancing avatars' powers.

\section{References}

[1] C. Heeter, "Being There: the subjective experience of presence", Presence: Teleoperators and Virtual Environments, 1(2), MIT Press, Cambridge, MA, 1992, pp. 262-271.

[2] B.G. Witmer, and M.J. Singer, "Measuring Presence in Virtual Environments: A Presence Questionnaire", Presence: Teleoperators and Virtual Environments, 7(3), MIT Press, Cambridge, MA, 1998, pp. 225-240.

[3] M. Slater, and A.J. Steed, "A virtual presence counter", Presence: Teleoperators and Virtual Environments, 9(5), MIT Press, Cambridge, MA, 2000, pp. 413-434.

[4] C. Dede, M. Salzman, R. Loftin, and K. Ash, "Using Virtual Reality Technology to Convey Abstract Scientific Concepts", in M. Jacobsen \& R. Kozma (Eds.), Learning the Sciences of the 21st Century: Research, Design, and Implementing Advanced Technology Learning Environments, Lawrence Erlbaum, Hillsdale, NJ, 1997.

[5] A. Naeve, and G. Taxen, "CyberMath: Exploring Open Issues in VR-Based Education", Proceedings of SIGGRAPH 2001, Educators Program, 2001, pp. 49-51.

[6] D. Bowman, J. Wineman, L. Hodges, and D. Allison, "The Educational Value of an Information-Rich Virtual Environment", Presence: Teleoperators and Virtual Environments, 8(7), MIT Press, Cambridge, MA,1999, pp. 317-331.

[7] K.E. Hay, B. Kim, and T.C. Roy, "Design-Based Research: More than Formative Assessment? An Account on the Virtual Solar System Project", Educational Technology, 
45(1), Educational Technology Publications, Englewood Cliffs, NJ, 2005, pp. 34-41.

[8] S. Kenderdine, "1000 Years of the Olympic Games: Treasures of Ancient Greece. Digital reconstruction at the home of the gods", Proc. Museums and the Web 01, Archives \& Museum Informatics, Pittsburgh, 2001.

[9] T. A. Mikropoulos, and V. Strouboulis, "Factors that influence presence in educational virtual environments", Cyberpsychology \& Behavior, 7(5), Mary Ann Liebert, Larchmont, NY, 2004, pp. 582-591.

[10] B. Johnson, "Place-Based Storytelling Tools: A New Look at Monticello", Proc. Museums and the Web 05, Archives \& Museums Informatics, Toronto, Canada, 2005.

[11] S. Roy, E. Klinger, P. Légeron, F. Lauer, and P. Nugues, "Definition of a VR-Based Protocol to Treat Social Phobia", CyberPsychology \& Behavior, 6(4), Mary Ann Liebert, Larchmont, NY, 2003, pp. 411-420.

[12] A.S. Carlin, H.G. Hoffman, and S. Weghorst, "Virtual Reality and Tactile Augmentation in the Treatment of Spider Phobia: A Case Report," Behaviour Research and Therapy, 35(2), Elsevier, Piscataway, NJ, 1997, pp. 153-158.

[13] B. Nelson, D.J. Ketelhut, J. Clarke, C. Bowman, and C. Dede, "Design-Based Research Strategies for Developing a Scientific Inquiry Curriculum in a Multi-User Virtual Environment", Educational Technology, 45(1), Educational Technology Publications, Englewood Cliffs, NJ, 2005, pp. 21-27.

[14] S. Barab, M. Thomas, T. Dodge, R. Carteaux, and H. Tuzun, "Making learning fun: Quest Atlantis, a game without guns", Educational Technology Research and Development, 53(1), Springer, Memphis, TN, 2005, pp. 86-107.

[15] M.U. Bers, "Identity Construction Environments: Developing Personal and Moral Values Through the Design of a Virtual City. The Journal of the Learning Sciences, Lawrence Erlbaum, Mahwah, NJ, 10(4), 2001, pp. 365-415. [16] Hall, E.T., The Hidden Dimension, Doubleday, Garden City, NY, 1966.

[17] P. Dourish, and V. Bellotti, "Awareness and Coordination in Shared Workspaces", Proc. ACM Computer
Supported Cooperative Work, ACM Press, New York, NY, 1992, pp. 107-114.

[18] S. Greenberg, C. Gutwin, and A. Cockburn, "Awareness Through Fisheye Views in Relaxed-WYSIWIS Groupware", Proc. Graphics Interface Conference, Morgan-Kaufmann, San Francisco, CA,1996, pp.28-38.

[19] T. Barbieri, "Networked Virtual Environments for the Web: The WebTalk-I and WebTalk-II Architectures", IEEE for Computer Multimedia \& Expo 2000 (ICME), New York, NY, 2000.

[20] A. Bucciero, L. Mainetti, and P. Paolini, "Flexible 3D Collaborative Virtual Environment: WebTalk04", Proc. Virtual Systems and Multimedia. Ghent, Belgium, 2005.

[21] T. Barbieri, P. Paolini, F. Alonzo, G. Gaia, and P. Loiudice, "Visiting a Museum Together: how to share a visit to a virtual world", Museums and the Web 1999, Archives \& Museum Informatics, Pittsburgh, 1999.

[22] N. Di Blas, P. Paolini, and C. Poggi, "Shared 3D Internet environments for education: usability, educational, psychological and cognitive issues", in J. Jacko \& C. Stephanidis (Eds), Human-Computer Interaction: Theory and Practice, Lawrence Erlbaum, Mahwah, NJ, 2003.

[23] N. Di Blas, P. Paolini, and C. Poggi, "3D Worlds for Edutainment: Educational, Relational and Organizational Principles", Proc. IEEE Workshop on Pervasive eLearning, IEEE Press, New York, NY, 2005, pp. 291-295.

[24] N. Di Blas, P. Paolini, and C. Poggi, "Educational benefits: testing and evaluation of a collaborative 3D world", Proc. ED-MEDIA 2005, AACE, Montreal, Canada, 2005.

[25] N. Di Blas, E. Gobbo, P. Paolini, "3D Worlds and Cultural Heritage: Realism vs. Virtual Presence", Proc. Museums and the Web '05, Archives \& Museum Informatics, Toronto, Canada, 2005.

[26] H.H. Clark, and S.E. Brennan, "Grounding in communication", in R. M. Baecker (Ed.), Groupware and Computer-Supported Cooperative Work, Morgan Kaufmann Publishers, San Francisco, CA, 1993, pp. 222-233. 